\title{
Discussion on the Construction of Recycling Logistics System of Express Package
}

\author{
Congli Xie \\ Bussiness School, Xi’an International University, Xi’an, 710077, China \\ Email: 54471753@qq.com
}

Keywords: Express packaging, Recycling logistics, Logistics system construction

\begin{abstract}
The development of e-commerce provides a kind of more convenient lifestyle for customers, they can buy what they need without going outside. Recently the amount of e-commerce business transactions has been increasing in our country, which lead to the requirement of express package is also increasing. These express packages are often thrown away as rubbish. Express garbage accounts for 15\% of life's waste in China 2016 ,which includes plastic ,rubber belt and so on ,those materials are not only hard to decompose ,but also can cause serious environment pollution .This paper tried analyzing it in different views from the necessity, feasibility, participants and objects of the recycling of these packages ,and discuss how to build a recycling logistics system about express package.

The prosperity of the express industry has been brought by the boom of e-commerce. According to the national post office issued '2016 statistics bulletin of the postal industry development' shows that in 2016, national consumption includes 20.7 billion express Courier waybill, 3.1 billion woven bag, 8.268 billion plastic bags, 8.268 billion covers, 9.922 billion packages, 2.977 billion internal buffer packing. These data implies that tens of thousands of tons of garbage is behind the prosperity of courier warehouse explosion.
\end{abstract}

\section{The necessity of constructing the logistics system of express package recycling}

\subsection{The need to protect the environment}

The rapid development of express delivery industry has brought a large number of consumption of packaging, due to the packaging products are mostly one-time consumables, as the products are consumed, the life of the packing also ended, especially widely used in packaging tape, plastic bags and other main materials, which cannot be natural degraded and handled by landfill and incineration, and need a long degradation period and the releasing chemicals will produce large amount of air hazards such as dust, sulfur dioxide to damage the environment. Therefore, it is necessary to establish a scientific and reasonable system of express package recycling for environmental protection.

\subsection{The need for rational utilization of resources}

The cost of packaging is further increased due to the complicated process for non-renewable or non-renewable resources. Such as nonrenewable metal packaging and difficult regeneration of glass packaging, due to the production process is relatively complicated and the production cost is higher, the disposal of these packages should be taken into recycling logistics system for second use, these effective resources allocation can be achieved effectively, but also reduces the cost of packaging.

\subsection{The need to save costs.}

The cost of express packaging will increase the social cost. If the cost of each express package is calculated at the average of 0.5 yuan per item, China's 31.2 billion express packages in 2016 costs 15.6 billion yuan,this data was amazing. Therefore, constructing a express package recovery system can effectively reduce the social cost and reduce the cost pressure. 


\section{The feasibility of building the express package recycling system}

\subsection{Helping to improve the competitiveness of enterprises}

With the increasing market competition and the transparency of commodity prices, the enterprises profit space of is shrinking constantly, which force enterprises to compress the cost continuously. However e-commerce companies generally protect commodities by increasing the intensity of their packaging, which in turn leads to higher packaging costs. Therefore, perfect packaging recycling system for the express company can reduce the investment of packaging capital, and then improve enterprise market competitiveness.

\subsection{Increasing awareness of environmental protection for consumers}

In recent years, global environmental pollution such as Marine pollution, air warming, haze, sandstorm and other problems are becoming more and more serious. Especially haze is forcing people to realize the importance of environmental protection. Nielsen was made in 2014 on the impact of a global corporate social responsibility on consumer survey, according to the survey, "Chinese corporate social responsibility and awareness of environmental protection concept are gradually thorough popular, consumers are also more emphasis on making purchase decision, this will be more conducive to the progress of environmental protection". The awareness of the environmental protection of the consumer groups has been initially set up, and the environmental problems brought by packaging are of great concern.

\subsection{Consumers want to reduce the cost of express delivery}

Packaging cost is ultimately bought by the consumer, but the consumer hopes to get a good price for the products, thus it is a game between the two. Although excessive packaging can meet the needs of protecting commodities, it damages the interests of consumers, so packaging enterprises, e-commerce enterprises and logistics enterprises should comply with the needs of consumers.

\section{Construction strategy of express package recycling system}

\subsection{The design of the participant in the express package recycling system}

\subsubsection{Express Enterprise}

In the construction of the package recycling logistics system, the express enterprises need to make the following efforts:

First, strengthen staff training. The express company should further strengthen the consciousness of employees' environmental protection and economy, establish a set of standardized packaging process, and carry out standardized operation.

Second, establish the recovery mechanism. A special recycling point should be set up to dispose the waste materials uniformly and integrate the materials that can be used again after secondary processing, packages that cannot be used again should be sent to the transfer center regularly for a unified treatment.

Third, the senders are encouraged to provide their own packaging materials. Express company can encourage the sender to provide packaging materials and reduce some fee in a reasonable range, which will improves the secondary utilization of the packaging, and reduces the express delivery cost, so as to achieve the goal of win-win.

Fourth, express enterprises should strictly prohibit violent operation. At present,much more e-commerce enterprises have to use multi-layer packaging to avoid barbaric operations. If express enterprises can completely eliminate this phenomenon, they can help e-commerce enterprises to solve their worries.

\subsubsection{Online shoppers}

In the construction of the package recycling system, consumers of online shopping need to establish green consumption awareness. With the raising of living standard the present consumption 
with excessive packaging, so the whole society should advocate appropriate packaging, eliminate the vanity heart, and advocate of consumer participation in supervision, which will plays a positive role in building packaging recycling logistics system.

\subsubsection{E-commerce enterprises}

In the construction of the whole package recycling logistics system, the sellers are faced with two problems: excessive packaging and the unrecyclable packaging materials. Excessive packaging is not only affected by the psychological demand of consumers, but also affected by the same industry competition, the cost of packaging is relatively small compared with that of electric business enterprises, so they have to be packed in layers to ensure the integrity of goods in order to avoid violence. This excessive packaging is not reasonable, the seller can work on the packaging technology and packaging methods to achieve the desired effect. In addition, the seller should also choose some green and environmental packaging when choosing the packing material.

\subsection{Optimization design of recycle object of logistics packaging material recovery system.}

\subsubsection{A reusable soft packaging bag.}

At present, the most commonly used by express companies are paper bags, self-adhesive bags (PAK bags), express bone bags, express woven bags and several other soft packaging bags. These soft packaging bags are quite difficult to recycle, and easy to form white pollution. Recycled design of soft packing bag can use with composite kraft paper and plastic or waterproof cloth, bag with drawstring or zipper for sealing, loosen the draw string or zipper can directly accessible to take out the goods, and the bag itself did not be damaged, which can be used into the second.

\subsubsection{Recyclable packaging cartons.}

At present, the packaging used by express company are mostly corrugated packaging. Corrugated packaging is damaged easily by moisture and anti-strike ability, and it is not in line with the need of recyclable packaging materials. The European paper industry giant drastically group developed "Protektapak" corrugated packaging, one piece of corrugated paper can withstand impact brought by the fall from $5 \mathrm{~m}$ high, which has a certain guiding significance for domestic express packaging industry. At the same time, zonestar uses 3A heavy duty corrugated board packaging box in addition to the high strength, good humidity resistance, easy recovery, this package meets the construction demand of logistics packaging recycling system.

\subsubsection{Recyclable foam box}

The foam box has the advantages of light weight, strong impact resistance, so it is commonly used in online shopping. but in the process of traditional express transportation, sellers tend to put on many layers of plastic tape in order to prevent bubble chamber in the transport process in the body and the lid off, but it requires a certain amount of manpower investment to clean up the plastic, which lead that the foam box second utilization possibility is reduced, so it is necessary to make some improvement on the foam box design:a dark slot, button, or some easy to relaxed.

\subsection{The process design of express package recycling logistics.}

\subsubsection{Dispatch on the spot}

Recycling on the spot after dispatching means the courier express delivery end, the consignee confirms and receipts, and then recover the package and give them cash compensation for the recipient, then these packages are took back by Courier to the company for processing into secondary use ,it is the most simple and quick recovery process.

\subsubsection{Post piece recovery, Post recovery}

In the case of delivery cannot be directly delivered to the recipient, there has three solutions: firstly the courier company could add packaging recycling outlets, and entrust courier generation recycle sent branch; Secondly in the case of using intelligent express box , the packages can be 
made by recipient in intelligent compartment, information sent by intelligent ark to express delivery company ,and then the courier company to take away the package; thirdly the recipient packs up the packing material, and directly agrees the time with courier, and then the courier comes to collect the package.

\section{Summary}

Science and technology is a double-edged sword, e-commerce brings people a convenient way of life, at the same time also left a lot of express packaging waste, if the packaging waste can reasonable use, it will have a strong practical value. Compared with developed countries, the returned logistics system development of China's express packages is relatively backward, but environmental protection and economic development have a strong demand on recycling courier packages. This paper has discussed some problems from the perspective of express delivery business, online consumers, sellers and the participation of the main body of packing materials recovery, recovery mechanism, and the packaging process and packing process, then it puts some forward feasible suggestions on how to build a Courier packages returned logistics system to save the cost of China express industry. It aims to protect the environmental as well as to contribute the development of electronic commerce.

\section{References}

[1] Supriya Mitra, Scott Webster. Competition in Remanufacturing and the Effects of Government subsidies [J], International Journal of Production Economics, 2008, (2)

[2] Teunter R. Lot-sizing for Inventory Systems with Product Recovery [J]. Computes and Industrial Engineering, 2004, (46)

[3] Anna Nagurney, Fuminori Toyasaki. Reverse Supply Chain Management and Electronic Waste Recycling: a Multitered Network Equilibrium Framework for E-cycling [J]. Transportation Research, 2005, (41)

[4] Li Gang. New trends in the development of China's packaging industry [J]. agricultural products processing (innovative Edition), 2012, (4)

[5] Shi Yu. Promote the green development of liyue to announce "environmental targets for 2020". [J].Green China, 2013, (4) 